\title{
Sexual Excitement as a Function of Stimulus Novelty Level and its Repetitions in a Male Pig-Tail Macaque (Macaca Nemestrina) Model (A Medical Hypothesis)
}

Dwi Atmoko Agung Nugroho*

Department of Primatology and multidiciplinary Program, Bogor Agricultural University Indonesia

\begin{abstract}
Aim: Sexual functioning is generally impaired during depression. This article would like to demonstrate a principle of behavior that can ultimately become a solution of sexual dysfunction by controlling the number of stimulus repetitions then this is an effective way to maintain the novelty of stimulation that can regain the excitement of behavior in terms of response time and duration.

Method: An eight years old male pigtail macaque model named "John" who lives in an individual cage $(5 \times 5$ $\times 5 \mathrm{~m}$ ). The researcher did an audio-visual stimulation as much as 1 time a day at 07.00 am (morning) and did the repetitions for 4 days in a row. Based on video recordings, then response times or arousal times into scratching behavior toward his sexual organs such as penis and anus by his hands and their behavior-duration analysed by using real time player in seconds.

Result and conclusion: So far, these result will have implication that if the number of repetitions of the stimulus decreased (thus kept the stimulus novelty level still) then the arousal times into the sexual response (scratching behavior) will be faster, and the duration of the sexual response (scratching behavior) will be longer as the number of repetitions of the stimulus decreases.
\end{abstract}

Keywords: Sexual excitement; Stimulus novelty; Repetition; Scratching behavior; A male pig-tail macaque (Macaca nemestrina)

\section{Introduction}

Sexual problems are associated with a reduction in the quality of life, and represent a major risk factor for the development of depression, and are often associated with other mental health problems [1]. Sexual functioning is generally impaired during depression [2]. Depression affected DISF (Derogatis Inventory of Sexual Function) domains differently: orgasm was most impaired, whereas sexual desire was preserved, more severe depression resulted in greater sexual dysfunction [3]. The severity of sexual dysfunction among patients with MDD (Major Depressive Disorder) was most correlated with the severity of the depressive dimension, but not the severity of the somatic dimension [4].

In human, sexual dysfunction is both a symptom of depression and an adverse effect of many antidepressants [5,6]. Most antidepressant drugs have adverse effects on sexual function [7], but accurate identification of the incidence of treatment-emergent dysfunction has proved troublesome, as disturbances of the sexual response can only be detected in a reliable fashion when systematic enquiries are made before and during the course of treatment [8]. Although Tianeptine is a new antidepressant drug with less adverse effects on sexual functions [9] but the multi factorial origin of both depression and sexual dysfunctions suggests that the right approach and treatment of the depressed patient includes not only the prescription of an antidepressant but also a global approach based on several axis that are concomitants namely: physiological, cognitive, emotional, behavioural and relational factors [10].

Cognitive distraction is a significant contributor to sexual response problems in men and women and is observed more consistently for genital arousal than for subjective arousal [11] although there was finding shown that being or not in a relationship seems to be a risk factor for sexual dysfunction [12]. There is need for collaboration between healthcare practitioners from different disciplines in evaluation, treatment, and education issues surrounding sexual dysfunction [13].
For human, Freud portrayed little Hans ("A Phobia in a Five Year Old Boy"), who was fascinated by his penis (his "widdler"), and whose immediate impulse when meeting any person or object was to examine it to see if it too had a widdler. Sexual curiosity starts, according to this first formulation, by the child discovering and taking pleasure in the sensations of his sexual organ [14]. That is why the decline in sexual excitement may become into a serious psychiatric problem that accompanies depression.

Here we try to propose the solution by decreasing the number repetitions of sexual-stimulation to keep its novelty based on findings that repetition-related reductions in neural activity [15] and the stimulus novelty was thought to increase and maintain the level of response of the excitement of a behavior due to it could triggers the amygdala activities [16], regardless that stimulus repetition in identification tasks leads to improved behavioral performance [17]. It rises to the hypothesis that the level of stimulus novelty will decrease if the number of repetitions was increased. If the level of novelty decreases then the response level of the sexual enthusiasm will also decrease in terms of response time and duration.

To improve sexual excitement and prevent sexual dysfunction in human societies while avoiding ethical complexities, here we used a model by male pig-tail macaque (Macaca nemestrina) who showing sexual excitement or sexual arousal when responding to stimulus novelty but decline by its repetitions as a model in a repeated-analyses method.

*Corresponding author: Dwi Atmoko Agung Nugroho, Department of Primatology and Multidiciplinary Program, Bogor Agricultural University Indonesia, Tel: +622518313637; E-mail: mokonugroho28@gmail.com

Received: May 17, 2017; Accepted: June 15, 2017; Published: June 30, 2017

Citation: Nugroho DAA (2017) Sexual Excitement as a Function of Stimulus Novelty Level and its Repetitions in a Male Pig-Tail Macaque (Macaca Nemestrina) Model (A Medical Hypothesis). J Psychiatry 20: 417. doi:10.4172/2378-5756.1000417

Copyright: $\odot 2017$ Nugroho DAA. This is an open-access article distributed under the terms of the Creative Commons Attribution License, which permits unrestricted use, distribution, and reproduction in any medium, provided the original author and source are credited 


\section{Materials and Methods}

The subject of the study was an eight years old male pigtail macaque named "John" who lives in an individual cage $(5 \times 5 \times 5 \mathrm{~m})$. The research place was an Animal Rescue Center in Tabanan, Bali Indonesia. The study time was 4 days. The operational definition of dependent variable here were the response times or arousal times into scratching behavior toward his sexual organs such as penis and anus by his hands and his behavior durations. The operational definition of independent variable (stimulation) here were the researcher existence (visually in front of the cage plus the short voice calling the subject-name) and its repetitions during 4 days.

\section{Procedures}

The researcher walked closer to the subject enclosure while carrying the video camera on the 'on' position, then calling the subject-name with short voice: "Hello John!" (when arrived in front of the cage). The researcher recorded the subject response at a distance of 0.5 meters from the cage. The researcher did this stimulation as much as 1 time a day at 07.00 am (morning) and did the repetitions for 4 days in a row. Based on video recordings, then response times or arousal times into scratching behavior and their duration analysed by using real time player in seconds.

\section{Results and Discussion}

Scratching behavior by John started with standing behavior previously. Most of them accompanied by sounding behavior or vocalizations but here we decided not to analysed it due to unstable distances between researcher and the subject during the observation time.

\section{Response times}

The response time to the 1 st stimulation was about 1 second (Video 1). The response time to the 2 nd stimulation was about 2 seconds (Video 2). The response time to the 3 rd stimulation was slower than the response time to the 1 st and 2nd stimulation, it was about 4 seconds (Video 3). At the 4th stimulation, it became a stage of boredom so that the sexual response (scratching behavior) did not appear at all but turns into a 'wondering' response or stereotypic behavior (Video 4). If the number of repetitions of the stimulus increased (thus lowering the stimulus novelty level slowly) then the arousal times into the sexual response (scratching behavior) will be slower as the addition of the number of repetitions of the stimulus (Table 1 and Figures 1 and 2).

\section{Durations}

The duration of response to 1st stimulation was longer than the duration of response to the 2nd stimulation, it was as long as 6 seconds (Video 1). The duration of response to the 2nd stimulation was shorter when compared to the duration of response to the 1st stimulation, it

\begin{tabular}{|c|c|c|c|}
\hline \multirow{2}{*}{ Repetitions } & \multicolumn{2}{|c|}{$\begin{array}{c}\text { Time schedules (please see the videos) in the } \\
\text { seconds }\end{array}$} & \multirow{2}{*}{$\begin{array}{l}\text { Response } \\
\text { times } \\
\text { (in } \\
\text { seconds) }\end{array}$} \\
\hline & $\begin{array}{l}\text { Stimulation -> (I said: } \\
\text { "Hello John!") }\end{array}$ & $\begin{array}{c}\text { Response-> Scratching } \\
\text { behavior }\end{array}$ & \\
\hline 1 & 00.00 .14 & 00.00 .15 & 1 seconds \\
\hline 2 & 00.00 .09 & 00.00 .11 & 2 seconds \\
\hline 3 & 00.00 .11 & 00.00 .15 & 4 seconds \\
\hline 4 & 00.00 .14 & No-scratching & 0 seconds \\
\hline
\end{tabular}

Table 1: The function of stimulus repetitions on response times into scratching behavior (sexual excitement)

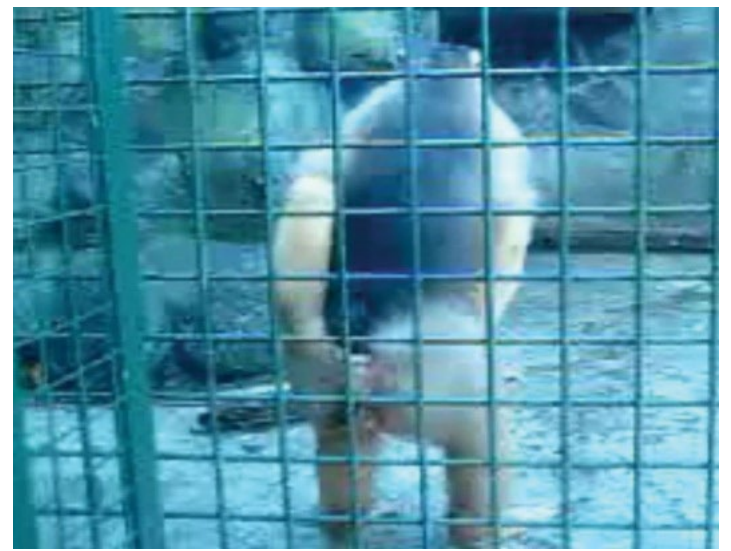

Figure 1: "John" standing and scratching his penis with the right hand and his anus with the left hand.

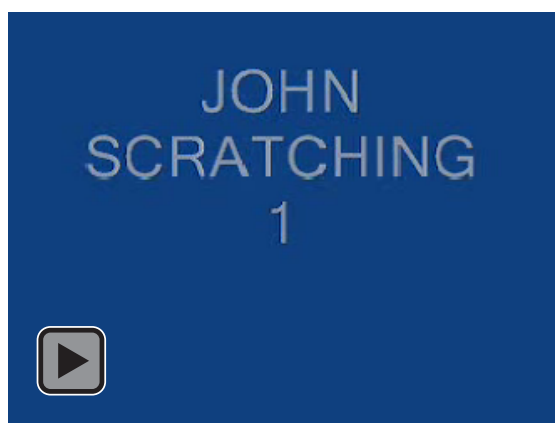

Video : 1

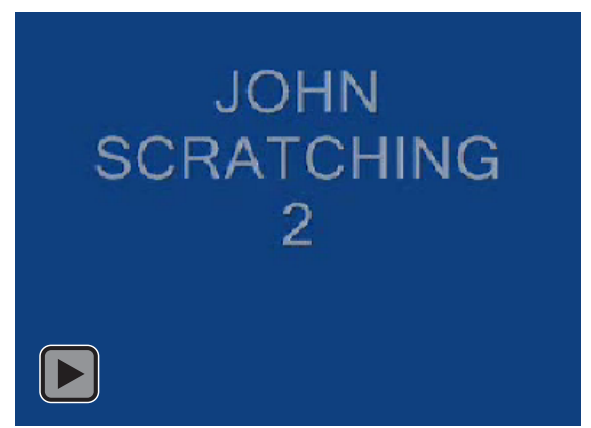

Video : 2

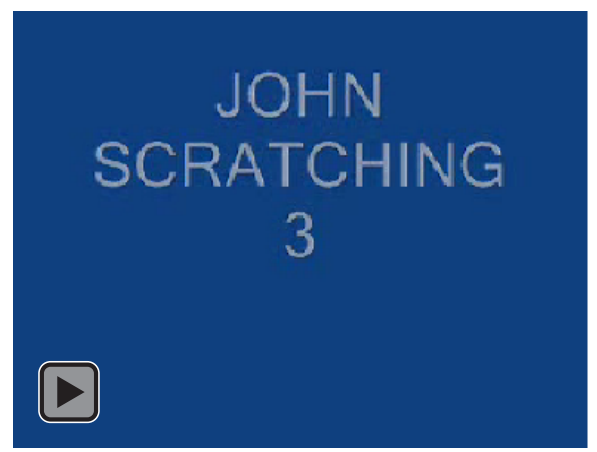

Video : 3 
Citation: Nugroho DAA (2017) Sexual Excitement as a Function of Stimulus Novelty Level and its Repetitions in a Male Pig-Tail Macaque (Macaca Nemestrina) Model (A Medical Hypothesis). J Psychiatry 20: 426. doi:10.4172/2378-5756.1000426

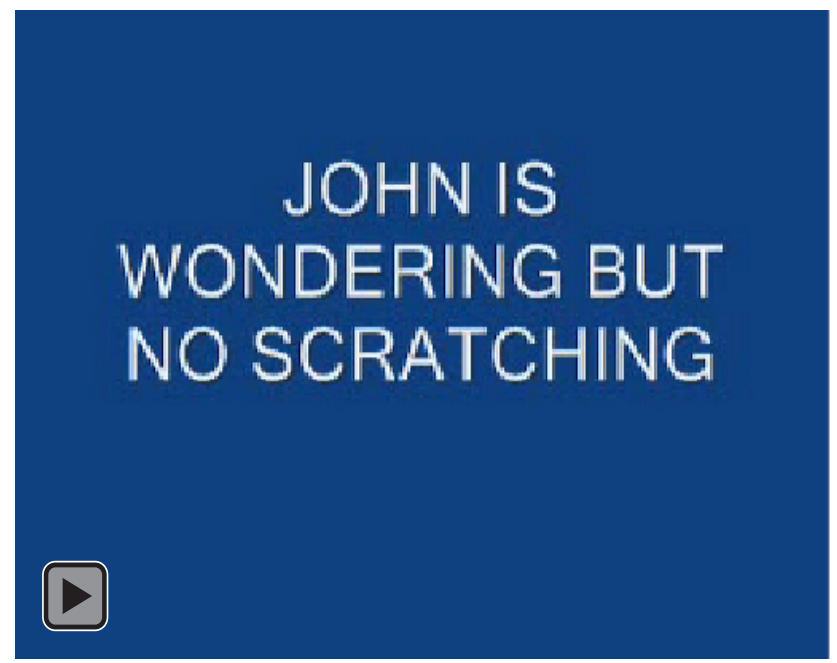

Video : 4

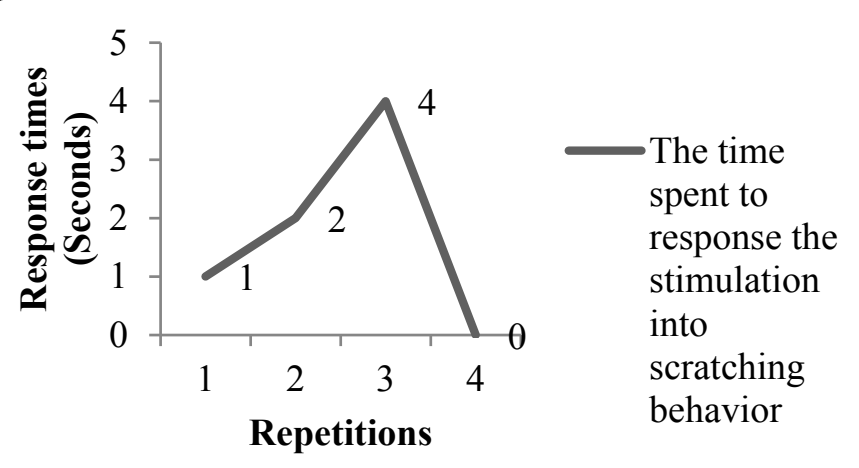

Figure 2: The function of stimulus repetitions on response times into scratching behavior (sexual excitement).

was as long as 5 seconds (Video 2). The duration of response to the 3 rd stimulation was shorter when compared to the response time to the 1st and 2nd stimulation, it was as long as 4 seconds (Video 3). As mention above, the 4 th stimulation became a stage of boredom so that the sexual response (scratching behavior) did not appear at all but turns into a 'wondering' response or stereotypic behavior (Video 4). If the number of repetitions of the stimulus were increased (thus decreasing the stimulus novelty level slowly) then the duration of the sexual response (scratching behavior) will be shorter as the number of repetitions of the stimulus increases (Table 2 and Figures 3 and 4).

These result could support the idea that although repetition under incidental-learning conditions could declined the memory of repeated items [18] so could kept its effect on excitement but prior item repetition reduces attention to subsequent presentations of the item, decreasing the likelihood that critical item-source associations will be encoded [19].

\section{Conclusion}

So far, these result will have implication that if the number of repetitions of the stimulus decreased (thus kept the stimulus novelty level still) then the arousal times into the sexual response (scratching

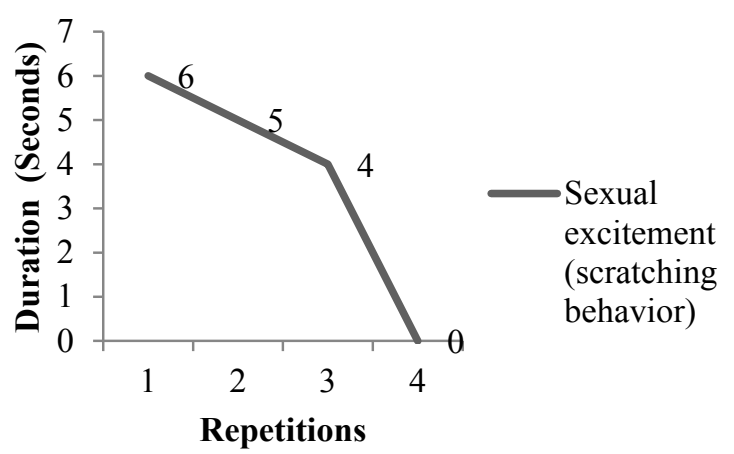

Figure 3: The function of stimulus repetitions on duration of scratching behavior (sexual excitement).

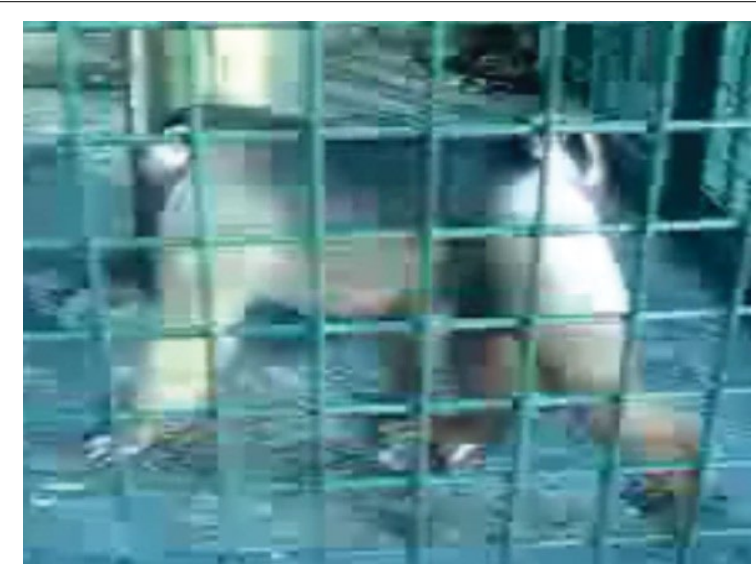

Figure 4: The boredom stage of the 4th stimulation (no scratching but wondering or did stereotypic behavior only).

\begin{tabular}{|c|c|c|c|}
\hline \multirow{2}{*}{ Repetition } & \multicolumn{2}{|c|}{$\begin{array}{c}\text { Time schedules (please see the videos) in the } \\
\text { seconds }\end{array}$} & $\begin{array}{c}\text { Durations } \\
\text { (in } \\
\text { seconds) }\end{array}$ \\
\cline { 2 - 3 } & Response-> Scratching behavior & Finish \\
\hline 1 & Start & 00.00 .21 & 6 seconds \\
\hline 2 & 00.00 .15 & 00.00 .16 & 5 seconds \\
\hline 3 & 00.00 .11 & 00.00 .18 & 4 seconds \\
\hline 4 & 00.00 .15 & No-scratching & 0 seconds \\
\hline
\end{tabular}

Table 2: The function of stimulus repetitions on duration of scratching behavior (sexual excitement).

behavior) will be faster, and the duration of the sexual response (scratching behavior) will be longer as the number of repetitions of the stimulus decreases.

This study attempts to explore the link of sexuality and novelty. The study was done on primate inside a cage. The behavior of animals in captivity may does not correlate with human behavior directly but here we could demonstrate the principle of such behavior in controlling sexual disturbances which can leads to psychiatric problems such as "Depression". As depression is the major and commonly occuring diseases in people and it is increasing day by day. The principle of this behavior can be one of the cause and so it can help to improve in some ways, thus we propose the result as a medical hypothesis due to the behavior of macaque which changed with the change in repetition of stimuli may also indicate other traits than sexual stimulation to novelty. 
Citation: Nugroho DAA (2017) Sexual Excitement as a Function of Stimulus Novelty Level and its Repetitions in a Male Pig-Tail Macaque (Macaca Nemestrina) Model (A Medical Hypothesis). J Psychiatry 20: 426. doi:10.4172/2378-5756.1000426

\section{Acknowledgements}

We thank drh. Bayu Wirayudha (head of FNPF), pak Putu, pak Ketut, and I Gusti "Samson" for their support and helps. This research was supported by Friends of National Park Foundation (FNPF).

\section{Statement of Interest}

The author declares does not has any conflicts of interest.

\section{References}

1. Bossini L, Fortini V, Casolaro I, Caterini C, Koukouna D, et al. (2014) Sexual dysfunctions, psychiatric diseases and quality of life: A review. Psychiatr Pol 48: 715-726.

2. Seidman SN, Roose SP (2001) Sexual dysfunction and depression. Current Psychiatry Reports 3: 202-208.

3. Fabre LF, Clayton AH, Smith LC, Goldstein IM, Derogatis LR (2013) Association of major depression with sexual dysfunction in men. J Neuropsychiatry Clin Neurosci 25: 308-318.

4. Lin CF, Juang YY, Wen JK, Liu CY, Hung Cl (2012) Correlations between sexual dysfunction, depression, anxiety, and somatic symptoms among patients with major depressive disorder. Chang Gung Med J 35: 323-331.

5. Kennedy SH, Rizvi S (2009) Sexual dysfunction, depression, and the impact of antidepressants. J Clin Psychopharmacol 29: 157-164.

6. Outhoff K (2009) Antidepressant-induced sexual dysfunction. SA Fam Pract 51: 298-302.

7. Baldwin DS, Foong $\mathrm{T}$ (2013) Antidepressant drugs and sexual dysfunction. $\mathrm{Br}$ J Psychiatry 202: 396-397.

8. Baldwin DS (2001) Depression and sexual dysfunction. Br Med Bull 57: 81-99.
9. El-Shafey H, Atteya A, el-Magd SA, Hassanein A, Fathy A, et al. (2006) Tianeptine can be effective in men with depression and erectile dysfunction. $J$ Sex Med 3: 910-917.

10. Reynaert C, Zdanowicz N, Janne P, Jacques D (2010) Depression and sexuality. Psychiatria Danubina 22: 111-113.

11. Brotto L, Atallah S, Agbakwu CJ, Rosenbaum T, Abdo C, et al. (2016) Psychological and interpersonal dimensions of sexual function and dysfunction. J Sex Med 13: 538-571.

12. Pereira VM, Nardi AE, Silva AC (2013) Sexual dysfunction, depression, and anxiety in young women according to relationship status: An online survey. Trends Psychiatry Psychother 35: 55-61.

13. Althof SE, Leiblum SR, Chevret-Measson M, Hartmann U, Levine SB, et al (2005) Psychological and interpersonal dimensions of sexual function and dysfunction. J Sex Med 2: 793-800.

14. Aronoff J (1962) Freud's conception of the origin of curiosity. J Psychol 54: 39-45.

15. Spector KG, Henson R, Martin A (2006) Repetition and the brain: Neural models of stimulus-specific effects. Trends Cogn Sci 10: 14-23.

16. Pedersen WS, Balderston NL, Miskovich TA, Belleau EL, Helmstetter FJ, et al. (2017) The effects of stimulus novelty and negativity on BOLD activity in the amygdala, hippocampus, and bed nucleus of the stria terminalis. Soc Cogn Affect Neurosci 12: 748-757.

17. Gotts SJ, Chow CC, Martin A (2012) Repetition priming and repetition suppression: Multiple mechanisms in need of testing. Cogn Neurosci 3: 250-259.

18. English MC, Visser TA (2014) Exploring the repetition paradox: The effects of learning context and massed repetition on memory. Psychon Bull Rev 21: 1026-1032.

19. Kim K, Yi DJ, Raye CL, Johnson MK (2012) Negative effects of item repetition on source memory. Mem Cognit 40: 889-901. 